\title{
HAZARD IDENTIFICATION APPROACH FOR FUTURE HIGHLY-AUTOMATED AIR TRAFFIC MANAGEMENT CONCEPTS OF OPERATION: EXPERIENCES FROM THE AUTOPACE PROJECT
}

\author{
FEDJA NETJASOV, BOJANA MIRKOVIC, TATJANA KRSTIC SIMIC \& OBRAD BABIC \\ University of Belgrade, Faculty of Transport and Traffic Engineering, \\ Division of Airports and Air Traffic Safety, Belgrade, Serbia
}

\begin{abstract}
In future air traffic management (ATM) a significant increase in automation is expected, in order to cope with growing air transport demand. The automation will take more active role during the provision of the air traffic control (ATC) services, while future air traffic controller (ATCo) will monitor and/or approve actions performed by automated ATC systems. ATCo will need to be trained to safely adapt to new role, with special emphasis to be prepared for active participation in the case of automated system failure (non-nominal situations). Developing appropriate training should rely on assessed safety hazards in future ATM. AUTOPACE project (funded by the SESAR Joint Undertaking within the framework S2020 Exploratory Research Programme as part of the Horizon 2020 programme) looks into 2050 and beyond. In order to assess safety hazards, an approach based on hazard identification brainstorming sessions with operational experts, combining four well known and complementary methods used in aviation is proposed. Future ATCo environment is observed through two main parts. Internal, core part contains ATCo and ATC system and their relations. External part (environment) gathers Local Traffic Manager, System Wide Information Management (SWIM), other ATC systems/ATCos and traffic (aircraft/pilot). Two expert brainstorming sessions were performed based on future tasks and description of nominal and non-nominal situations which were defined at the beginning of the project. One, with academic experts, resulted with initial set of hazards. The second, with operational experts (experienced ATCos), provided a validation of the initial set and some additional, complementary hazards. Final output from both sessions is the list of "operation specific" (general) and "task specific" hazards identified. Those hazards are subject to further characterization (assignment of severity and likelihood), aiming to determine safety critical hazards that will serve as an input for development of new training methods for future ATCos.

Keywords: risk assessment, hazard identification, air traffic management, air traffic control.
\end{abstract}

\section{INTRODUCTION}

The air transport system belongs to a class of complex, human-centred and safety-critical industries. Constant growth in air transport demand has many positive effects on the global economy, but providing additional capacity to accommodate such demand, can have a negative impact, primarily related to safety of operations. Safety and capacity are mutually conflicting goals, and tendency to further increase system capacity could put system safety at danger. Increasing capacity without decreasing system safety requires the development of new technologies, operational procedures and corresponding regulations [1].

This capacity-safety relationship also applies for the Air Traffic Management (ATM) system. Further growth in air transport demand requires changes in ATM system. These changes lead to further system evolution, i.e. to synchronized changes in procedures, pilot and Air Traffic Controller (ATCo) operating methods, airborne and ground-based systems, legislative and regulatory frameworks, and aeronautical data sources. All those changes have to be introduced carefully because it could jeopardize system safety [1]. 
Two ongoing programs dealing with the definition of the future air transport systems are Single European Sky Air Traffic Management Research (SESAR) and U.S. Next Generation Air Transport System (NextGEN). The main goal of both programs is to increase system capacity cost-effectively, while ensuring safety. The common vision is to integrate and implement new technologies to improve ATM performance. Both combine increased automation with new procedures, in order to achieve safety, economy, capacity, environmental and security benefits.

In future ATM, a significant increase in automation is expected, in order to cope with growing air transport demand. The automation will take more active role during the provision of the air traffic control (ATC) services, while future ATCo will monitor and/or approve actions performed by automated ATC systems. ATCo will need to be trained to safely adapt to new role, with special emphasis to be prepared for active participation in the case of automated system failure (non-nominal situations). Developing appropriate training should rely on assessed safety hazards in future ATM. This is the main goal of AUTOPACE project which looks into 2050 and beyond.

The aim of the research presented in this paper is to provide insight into main factors affecting safety, to identify safety issues, and finally to provide suggestions on how to cope with the critical safety issues related to future ATM operations.

In Section 2 an overview of AUTOPACE system is presented. Section 3 describes hazard identification as the most important step in the risk management process. Section 4 presents hazard identification approach developed and used in AUTOPACE, the outcome of which is summarized in Section 5. Section 6 provides conclusion of the hazard identification process and further research steps that will proceed.

\section{AUTOPACE SYSTEM}

In the process of safety assessment, the system is commonly observed through its three generic elements (Fig. 1 [1]) that are people, equipment and procedures, which exist and operate in the specific system environment (AUTOPACE project is limited to en-route environment). The interactions between the system elements one to another and each element to the environment are important to take into consideration.

The people element represents all the people working on the first line of operations, such as ATCos and pilots, as well as other staff working in the "background", such as dispatchers, local traffic managers, etc. The people element also encompasses the roles, responsibilities and functions of the people in the system (surveillance, communication, navigation, guidance, etc.), as well as the features that they bring to the system (workload, situational awareness, fatigue, errors, etc.).

Apart from the aircraft itself, equipment also includes all airborne- and ground-based equipment and tools used for guidance, surveillance, communication, navigation, etc. purposes. Also, it contains equipment used for prediction, detection and resolution of conflict situations - "safety nets", and other decision support tools used during operation.

Procedures refer to a set of rules that ATCos are expected to follow (comply with) in all meteorological and traffic situations, using available equipment. These include aircraft separation procedures, procedures of communication between ATCos and pilots, etc.

The environment consists of all exogenous influences on the air transport system, which can be controllable (by applying certain measures, e.g., air traffic demand) or not controllable (e.g., meteorological conditions). 


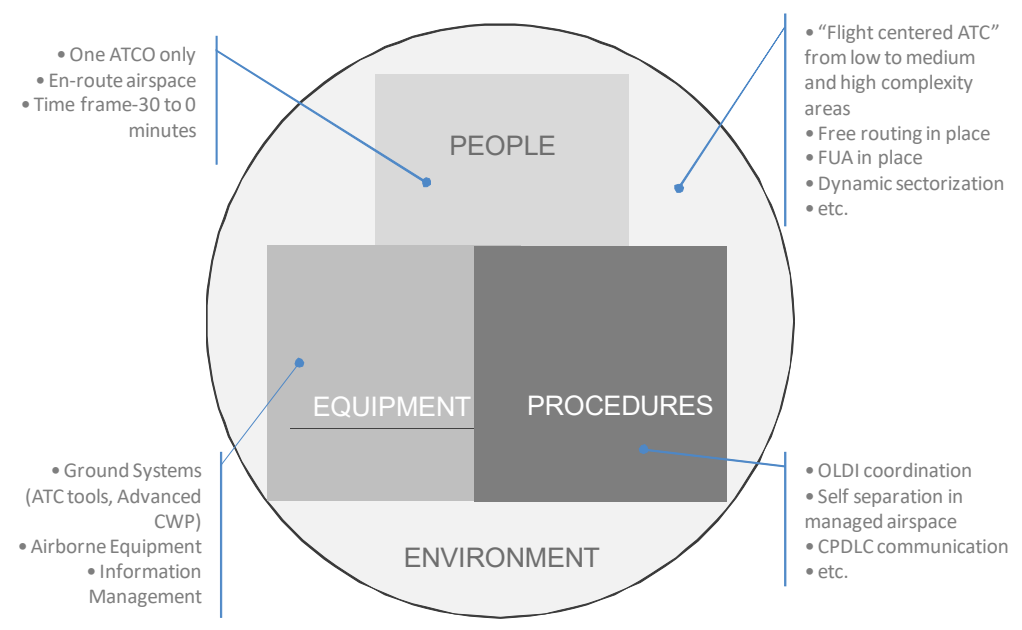

Figure 1: System elements.

\subsection{Future automation scenarios}

2050 AUTOPACE Concept of Operations [2], has been defined on the basis of the state of the art on future automation perspective in ATM in 2035 [2], and the possible directions for its further evolution (2050 and beyond). Future ATM will be rather different than current ATM system. The sectors will evolve to significantly larger geographical areas, within which ATCo will be in charge for the certain number of flights (Flight Centric ATC). Supported with automation, one ATCo is assumed to take over both current roles: Executive and Planner Controller role. Free routing will apply. Airlines will file their desired trajectories that will pass through de-confliction process on the planning level and will negotiate with ATC service providers about their trajectories. Once agreed on modified trajectories they will become so called 4D contract, i.e., it will be guaranteed that trajectories will be conflict free along the way as long as airlines stick to it.

Two Future Automation Scenarios are identified in AUTOPACE project [2]: High Automation Scenario (S1) and Medium Automation Scenario (S2), presenting two independent visions for ATM system in 2050. In S1 extreme case is assumed - ATS System takes over all major ATC responsibilities, while ATCo acts only as a supervisor of the ATC system. In S2, somewhat more active role of the ATCo is assumed - ATC System proposes alternatives of the actions to be performed, while ATCo decides which action to apply from the set of proposals given by the ATC system.

All tasks performed from 30 min prior to assuming the flight, until its transfer to another ATC System/ATCo is observed. List of 28 tasks is identified in [2]. Table 1 shows the share of responsibilities for the task execution between ATC System and ATCo.

Three verbs describe possible ATC System responsibilities:

- Apply: The ATC System analyses the situation, decides and implements the most suitable solution on his own according to available information;

- Propose: The ATC System proposes to the ATCo a set of actions to implement; and 
- $\quad$ Support: When needed, ATC System supports the ATCo decisions by providing him/her necessary information, ATCo responsibilities can also be threefold.

- Monitor: When the ATC System assumes the major ATC actions, the ATCo must monitor system behaviour to prevent deviations;

- Approve: Once the ATC System has proposed an ATC action, the ATCo must approve it before being implemented. Approval requires previous monitoring, but also an evaluation of the correctness of the ATC System decision;

- Apply: The ATCo analyses the situation, decides and implements the most suitable solution from a set of provided ATC System solutions and with the support of the ATC tools. Apply requires monitoring too but, in contrast to approve, it is the ATCo who must elaborate the solution to the problem and then identify and implement the necessary actions to carry it out.

Table 1: Share of responsibilities for the task execution between ATC System and ATCo in Scenarios 1 and 2.

\begin{tabular}{|c|c|c|c|c|}
\hline Responsibility & Tasks & S1 & & 52 \\
\hline $\begin{array}{l}\text { Plan conflict free } \\
\text { paths }\end{array}$ & 7,8 & Apply/Monitor & \multicolumn{2}{|c|}{ Apply/Monitor } \\
\hline $\begin{array}{l}\text { CDM with LTM i.e. } \\
\text { determine the needs } \\
\text { for complexity } \\
\text { solution measures }\end{array}$ & 20 & Propose/Approve & \multicolumn{2}{|c|}{ Support/Apply } \\
\hline Identify Conflict Risk & 1 & Apply/Monitor & \multicolumn{2}{|c|}{ ATC System } \\
\hline $\begin{array}{l}\text { Early Conflict } \\
\text { Detection and } \\
\text { Resolution }\end{array}$ & 6 & Apply/Monitor & \multicolumn{2}{|c|}{ Propose/Approve } \\
\hline $\begin{array}{l}\text { Coordination and } \\
\text { Transfer }\end{array}$ & $15,16,17 *, 28$ & Apply/Monitor & Support/Apply & $\begin{array}{c}* \\
\text { Propose/Approve }\end{array}$ \\
\hline Monitoring & $23-27$ & Apply/Monitor & \multicolumn{2}{|c|}{ Support/Apply } \\
\hline Separation provision & 9,10 & Apply/Monitor & \multicolumn{2}{|c|}{ Support/Apply } \\
\hline Implement solutions & $11,12,13,18$ & Apply/Monitor & \multicolumn{2}{|c|}{ Propose/Approve } \\
\hline $\begin{array}{l}\text { Input changes into } \\
\text { Flight Data } \\
\text { Processing System }\end{array}$ & 14,19 & Apply/Monitor & \multicolumn{2}{|c|}{ Support/Apply } \\
\hline $\begin{array}{l}\text { Communication - } \\
\text { provide information } \\
\text { and alerting service }\end{array}$ & $2,3,4,5,21^{*}$ & Apply/Monitor & Apply/Monitor & * Support/Apply \\
\hline $\begin{array}{l}\text { Special instructions } \\
\text { e.g. Holding }\end{array}$ & 22 & Propose/Approve & \multicolumn{2}{|c|}{ Support/Apply } \\
\hline LEGEND: & $\begin{array}{c}\text { Apply/Monitor } \\
\text { Propose/Approve } \\
\text { Support/Apply }\end{array}$ & $\begin{array}{l}\text { ATC System finds a } \\
\text { ATC System sugges } \\
\text { ATCo finds and apt }\end{array}$ & $\begin{array}{l}\text { applies the solu } \\
\text { olutions, ATCo c } \\
\text { es the solutions }\end{array}$ & $\begin{array}{l}\text { proves one } \\
\text { prove }\end{array}$ \\
\hline
\end{tabular}




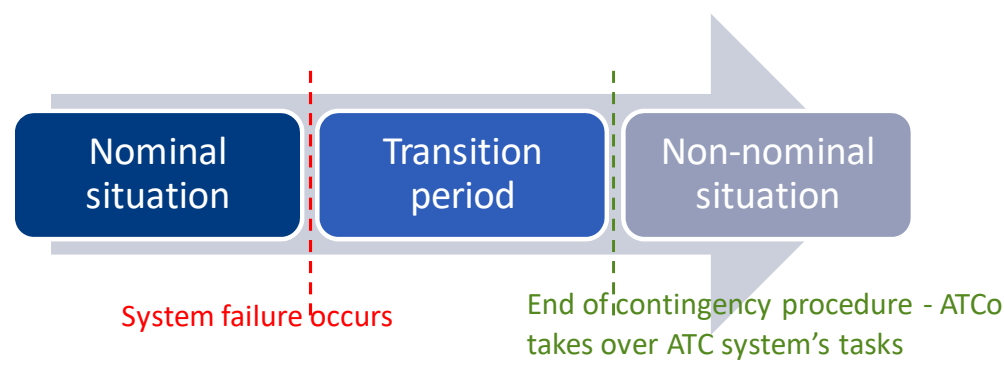

Figure 2: Transition from nominal to non-nominal situation.

\subsection{Non-nominal situations}

An automation failure or a malfunction in the service provision of one or several ATC tools is considered as non-nominal situations. Three non-nominal situations are addressed in AUTOPACE project [2]:

1. The Conflict Detection and Resolution tools failure;

2. The Complexity management tools failure;

3. The System supported coordination tools failure;

The occurrence of each of these failures in S1 and S2 results in eight scenarios in total (two nominal and six non-nominal situations). In all three non-nominal situations the ATCo will need to change his/her mode of operation i.e. to take over certain set of tasks performed by the ATC System in regular (nominal) conditions. Such situations present the main challenge in designing training for the future ATCo.

Once ATC System failure occurs, there is transition period in which ATCo should follow contingency procedure i.e. perform set of actions that enable taking over responsibilities for given set of tasks from ATC System, see Fig. 2. Transition from nominal to non-nominal situation is highly important to be considered in safety analysis.

\section{NOTION OF HAZARD}

The International Civil Aviation Organization (ICAO) defines risk management as "the identification, analysis and elimination of those hazards, as well as the subsequent risks, that threaten the viability of an organization". Risk management serves to focus safety efforts on those hazards posing the greatest risks [1], [3], [4].

The concept of risk management has equal application in decision making in [4]: flight operations, air traffic control, maintenance, airport management, and state administration. Risk management presents "a formalized way of dealing with hazards", and it is "the logical process of weighing the potential costs of risks against the possible benefits of allowing those risks to stand uncontrolled" [1], [5].

Recognizing hazards is the most critical step in the risk management process. Two aspects are very important:

- Understanding hazards - the proper identification and labelling of hazards is necessary in order to describe the nature and damaging potential of the hazards, to correctly infer the sources or mechanisms of the hazard, and to evaluate the 
outcomes (other than extreme outcomes) in terms of the magnitude of potential loss; and

- Hazard identification - the scope for hazards in air transport is wide, as is the variety of sources of the identified hazard (some sources are internal to the organization while others are external). Hazards may be identified through actual safety events (accidents or incidents), or they may be identified through proactive and predictive processes aimed at identifying hazards before accidents or incidents occur. In practice, both reactive measures and proactive processes provide an effective means of identifying hazards.

Hazards are often confused with the consequences. There are important differences between these two terms. Namely, a "hazard is defined as a condition or an object with the potential to cause injuries to personnel, damage to equipment or structures, loss of material, or reduction of ability to perform a prescribed function".

A hazard is anything that might negatively influence safety or an event or situation with possibly harmful effects [1]. A hazard can also be defined as an event/state that may: lead to a dangerous situation, or hamper resolution of such a situation, possibly in combination with other hazards or under certain conditions [6]. Hazards may emanate from the operational concept itself (e.g., related to the proposed hardware, software, procedures, and/ or human elements), from the external events in the environment (e.g., bad weather), or from failures or events in the system and/or other systems that can affect the system under consideration [7]. Hazards belong to the present. On the other hand, a consequence is defined as the potential outcome of a hazard. Consequences belong to the future [1], [4].

The main difficulty of hazard identification is to know when a hazard identification exercise is complete because there are many things to consider, especially in terms of interactions between system elements. The main challenge involves shifting the boundary between imaginable and unimaginable hazards. That means hazard identification is a neverending process which should be continuously carried out. The main output of hazard identification is a defined set of hazards which number in a certain system is infinite [1], [7].

\section{HAZARD IDENTIFICATION APPROACH}

Generally, hazards may be identified through a quantitative (data-driven) or qualitative process such as discussions, interviews and brainstorming. AUTOPACE project is specific because it looks in a far future -2050 and beyond so qualitative process is single option. This fact together with fact that details for future automation are uncertain makes hazard identification process very challenging. In order to assess safety hazards, an approach based on hazard identification brainstorming sessions with operational experts, combining advantages of four well known and complementary methods used in aviation is proposed [1]:

- Brainstorming sessions with operational experts [8] (focused on operational hazards);

- Functional Hazard Assessment [9] - FHA (focused on technical hazards);

- Future Aviation Safety Team [10] - FAST (focused on areas of change);

- Structured What If Tool [1] - SWIFT (carried out on a higher-level system description which is case in AUTOPACE project). 


\subsection{System components and their interactions}

The system observed in safety analysis is consisting of core part, environment and their interactions (Fig. 3). The core elements of the system are main actors - ATC System and ATCo. The environment consists of all external elements such as: Local Traffic Manager (LTM) involved in de-complexion process, other ATC System/ATCo (depending on the scenario), Aircraft/Pilot that receives instructions and data/information exchange (System Wide Information Management - SWIM).

In the S1 (Fig. 3, left), the ATC System develops the necessary actions for the orderly and safely traffic management, informing the ATCo of the actions developed if requested. The ATCo is expected to have the responsibility of monitoring or monitoring and approving in the provision of the majority of the ATC services. All tasks in S1 are performed by the ATC System, except two tasks requiring involvement from ATCo.

In the S2 (Fig. 3, right), the ATCo will be responsible not only for monitoring and approving, but also for applying many of the ATC services. The ATC System will propose set of actions or ATCo will decide about actions to be performed with support of ATC tool. In S2 there are still some tasks performed by the ATC System, but majority of the tasks require active role of the ATCo, whether it is to approve one of the proposed solutions by the ATC System, or to decide the actions while having the support from ATC tools.

\subsection{HAZID brainstorming sessions}

Two expert brainstorming sessions (Hazard Identification - HAZID) were performed based on future tasks and description of nominal and non-nominal situations which were identified at the beginning of the AUTOPACE project. One (HAZID 1), with academic experts (in the field of ATM and safety), resulted with initial set of hazards. The second (HAZID 2), with operational experts (experienced ATCos), provided a validation of the initial set and some additional, complementary hazards.

During HAZIDs, special attention was paid to the list of tasks (28 of them [2]) and how they are distributed among actors (ATCo and ATC System). It was important to clearly understand the actions related to each of the tasks. Reliance on advantages of four hazard identification methods previously mentioned was crucial for success of both HAZIDs.

Having in mind a main consequence of future automation (ATC System more active role, ATC Controller less active role) two main sources of hazards are identified:

- A hazard can be the result of a system or component failure (failure and hazard are frequently linked), but it is not always the case, and

- A hazard can exist without anything failing - e.g. the human errors and mistakes can often lead to hazards.

In AUTOPACE it is assumed that ATC System performs its tasks correctly i.e. its failures are limited strictly to three non-nominal situations. Possible corruptions of some functions (such as data link, HMI, ATC support tools) were also considered. The main focus of this project was on ATCo and tasks he/she performs.

Human errors are the consequence of intentional or unintentional human behaviour. Depending on the degree of intentionality preceding them they can be divided into the following categories [1], [11]: 


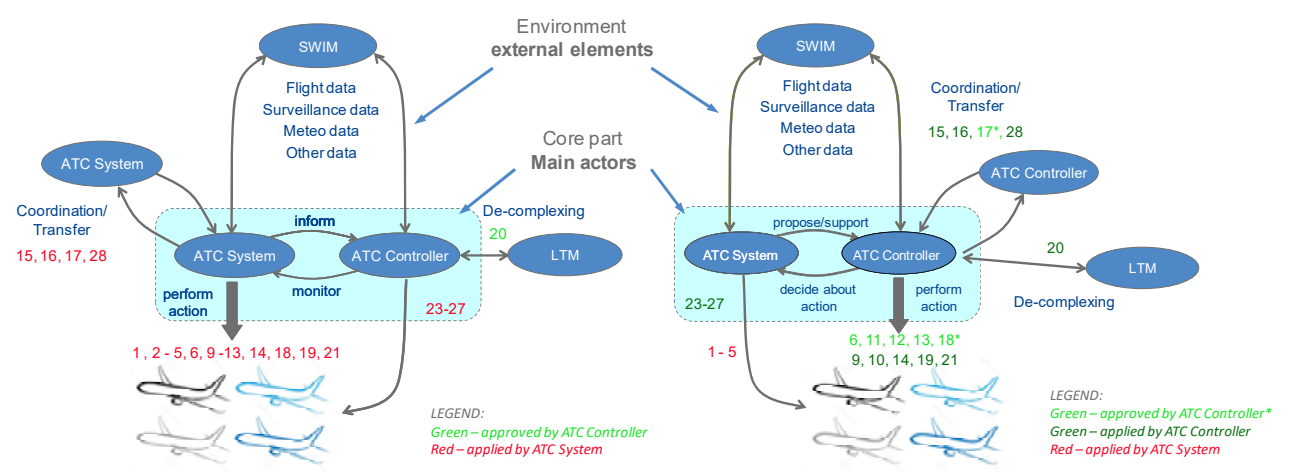

Figure 3: System elements and their interactions (left S1, right S2).

- $\quad$ slips - unintentional actions resulting from a lack of appropriate attention caused by distractions, miss-ordered sequences or miss-timed actions;

- lapses - unintentional actions caused by a memory failure arising from forgetting one's intention, losing one's place or omitting planned items;

- mistakes - intentional actions resulting from errors in planning without any deliberate decision to contravene established rules or procedures.

Slips and lapses are "conditioned or automatic responses, with little, if any, conscious decision making", while mistakes "involve deliberate decision-making and evaluation, based on knowledge, experience and mental models that have worked well in the past". Also related to mistakes are violations, which are not errors. Violations involve intentional planning failures, often based on knowledge and the mental models acquired through daily experience, but also involve a deliberate decision to contravene established rules or procedures [1], [11].

Furthermore, having observed future ATM system, with very high-level definition, sources of hazards can be also procedures and system design related issues. If some aspect is not defined or not defined to enough depth, it is desirable to have them listed as potential hazard, thus drawing the attention to system designers to address those issues prior to system implementation.

\section{HAZARDS IDENTIFIED}

During hazard identification, it was noticed that some hazards (or group of hazards) are relevant for the particular scenario/situation in general - operation specific, while other hazards are task specific. Among operations specific hazards special attention is given to transitional hazards - only in non-nominal situations.

After both hazard identification sessions (HAZID 1 and HAZID 2), a final set of hazards is produced (Table 2). Number of hazards per scenario/situation is given as total. It should be noted that the same hazards (or group of hazards) can be associated to various tasks (or group of tasks) in the same scenario/situation and/or repeated in different operational environments (scenarios). It could be also seen that greater number of hazards is identified in the case of S2 which resulted from the more active role of ATCo in this scenario. 
In order to be consistent and comprehensive in hazard identification and, later, with hazard characterisation (assignment of severity and likelihood to each hazard), for all observed scenarios/situations and types of tasks, hazards were categorized with respect to several criteria:

1. Responsibility share,

2. Nature of hazard,

3. Origin of hazard (Internal/External).

According to responsibility share types, three combinations of ATC System/ATCo responsibilities were recognized in the future ATC system - Hazard category I (only task specific hazards can be categorized in such a way):

I-1 Apply/Monitor

I-2 Propose/Approve

I-3 Support/Apply.

Depending on the scenario (S1 or S2, nominal or non-nominal situation), for each task, combinations of ATC System/ATCo responsibilities (Hazard category I) were assigned [2]. This responsibility share was very important for hazard identification, triggered with performing of the specific task, and latter, for severity and likelihood evaluation.

Nature of hazard can be various (Hazard category II). Seven groups are recognized and one additional that gathers all the remaining hazards:

II-1 Incorrect input

II-2 Incorrect action

II-3 Non-performable action

II-4 Reduced SA

II-5 Tool corruption

II-6 Uncertain traffic evolution

II-7 Other.

II-8 Undefined responsibility

Further, related to components of the system as a whole, five groups of hazards (Hazard category III) are identified:

III-1 ATC System

III-2 ATCo performance

III-3 Communication

III-4 Coordination

III-5 Other

Hazards III-1 and III-2 are internal hazards, i.e. belong to the core part of the system. Rest of them belong to the environment, i.e. external part of the system.

\subsection{Operation specific hazards}

Operation specific hazards are hazards that are typical for the scenario as a whole. Transitional hazards appear only in non-nominal situation and are related to transition period between nominal and non-nominal scenarios, during which ATCo needs to complete contingency procedure (see table 2). 
Table 2: Number of hazards (different types) per scenario/situation.

\begin{tabular}{|l|c|c|c|c|c|c|}
\hline \multirow{2}{*}{ Situation } & \multicolumn{2}{|c|}{ High Automation Scenario (S1) } & \multicolumn{3}{c|}{ Medium Automation Scenario (S2) } \\
\cline { 2 - 7 } & $\begin{array}{c}\text { Task } \\
\text { specific } \\
\text { hazards }\end{array}$ & $\begin{array}{c}\text { General } \\
\text { hazards }\end{array}$ & $\begin{array}{c}\text { Transitional } \\
\text { hazards }\end{array}$ & $\begin{array}{c}\text { Task } \\
\text { specific } \\
\text { hazards }\end{array}$ & $\begin{array}{c}\text { General } \\
\text { hazards }\end{array}$ & $\begin{array}{c}\text { Transitional } \\
\text { hazards }\end{array}$ \\
\hline $\begin{array}{l}\text { Nominal } \\
\text { situation }\end{array}$ & 101 & 9 & $\begin{array}{c}\text { not } \\
\text { applicable }\end{array}$ & 150 & 12 & not applicable \\
\hline $\begin{array}{l}\text { Non- } \\
\text { nominal } \\
\text { situation 1 }\end{array}$ & 158 & 16 & 10 & 173 & 13 & 10 \\
\hline $\begin{array}{l}\text { Non- } \\
\text { nominal } \\
\text { situation 2 }\end{array}$ & 88 & 11 & 10 & 133 & 12 & 10 \\
\hline $\begin{array}{l}\text { Non- } \\
\text { nominal } \\
\text { situation 3 }\end{array}$ & 116 & 13 & 10 & 151 & 13 & 10 \\
\hline
\end{tabular}

Majority of operation specific hazards are important for both S1 and S2, like the following:

- Hazards related to ATCo performance/Reduced situation awareness (SA) (category III-2/II-5), e.g. Reduced SA due to boredom (out-of-the-loop effect, i.e., overconfidence)/overload (fear of automation effect)/ fatigue; Omission of ATCo to carry out prescribed procedures; ATCo confusion about responsibility over specific flights, etc.

- Hazards related to ATC System/Tool corruption (categories III-1/II-6), e.g. Corruption/temporary failure of data-link, HMI or any other support function.

Some of the general hazards are typical only for S1 situations, when automation takes the major role, e.g.

- Skill degradation - wrong evaluation, reaction time too long, procedure mistakes etc.,

- Impossibility to take over control from the ATC System, etc.

Hazards typical for transition phase from nominal to non-nominal situations, when ATCo needs to change his/her mode of operation, i.e. takes over certain set of tasks regularly performed by ATC System in nominal situation, e.g.

- Hazards related to ATCo performance/Reduced SA (category III-2/II-5). Some of them are the same as general hazards for S1/S2 mentioned above, but they will be characterized (severity and likelihood) differently then hazards related to detection of the some of the function failure, etc.

- Hazards that indicate too slow transition process, categorized as ATCo performance/Other (category III-2/II-8),

- Specific, but very important hazards related to Other/Undefined responsibility (category III-5/II-4): Lack of contingency procedure and Unclear responsibility share between ATCo and ATC System, etc. 


\subsection{Task specific hazards}

Great number of task specific hazards is identified (Table 2). Some hazards (or group of hazards) are repeated for the certain tasks (or group of tasks) in the same or even different operational environments (scenarios). Some of the typical groups of hazards are the following-

- Hazards related to ATCo performance, attention, skills etc. (category III-2/II5) are identified for great number of tasks, e.g.:

- Skill degradation (wrong evaluation, reaction time too long, procedure mistakes etc.) - the hazard important in non-nominal situations, primarily when conflict detection and resolution tools fails,

- ATCo SA reduced due to high taskload/ too much information shown, etc.;

- Hazards from the same (ATCo performance/Reduced SA, III-2/II-5) category, but identified only for the specific tasks, are:

- Conflict risk not identified between aircraft,

- ATCo not aware of separation violation between certain pair of aircraft,

- ATCos confused about responsibilities over flights in conflict,

- all identified for non-nominal situations when conflict detection and resolution tools fails, etc.

Great number of task specific hazards is related to human errors slip/lapse/mistake/violation (category Incorrect action, II-2, except lapse that is Reduced SA, II-5). Slip is related to Communication (III-3), lapse and mistake to ATCo performance (III-1) and violation to Other (III-5).

Slip and Lapse are associated to the tasks related to information provision or giving the instruction, when ATC system/ATCo responsibility share is Support/Apply (I-3) or Propose/Approve (I-2), i.e., when ATCo should issue or input the data, solutions, etc. Mistake and violation can occur in the tasks related to coordination and finding the solution for separation provision, re-routing, sequencing etc., only when ATC system/ATCo responsibility share is Support/Apply (I-3). Mistake and violation are not possible for Propose/Approve (I-2) responsibility share, since the system is proposing the solution.

Hazards related to incorrect data in the system data-base SWIM (Communication/Incorrect input, III-3/II-1) are very important hazards since the ATC system and/or ATCo monitor traffic situation and make decisions based on those data.

One of the most important group of hazards identified belongs to the category Coordination/Undefined responsibility (III-4/II-4) and assumes lack of "master system" or "master" ATCo, when solution requires communication between various ATC Systems/ATCos.

Hazard related to data link corruption are associated only to the tasks that involve implementation (communication) of the solution and to the tasks related to providing some additional information to pilots. Hazards related to the corruption/temporary failures of the support tools (other than data-link) can occur in the tasks where decision is made with support of the tool, etc. Both belong to category ATC System/Tool corruption (III-1/II-6).

Some hazards are related to pre-tactical decisions that can evolve in an undesired way due to various circumstances (e.g., Transfer given too early). Vast majority of them are categorized as Other/Uncertain traffic evolution (III-4/II-7). Also, few hazards related to 
actions that cannot be performed (category Other/Non-performable action, III-4/II-3) are recognized in some of the tasks (e.g., Sector boundaries cannot be adapted to traffic routes).

\subsection{Risk mitigation related "categorization" of hazards identified}

In order to provide proper safety feed-back, it is important to identify hazards with significant safety issues, but also to distinct between various types of hazards with respect to measures needed to decrease the level of risk - mitigation measures.

Some hazards are related to system functioning and data accuracy, and it is not possible to mitigate safety problems, possibly caused by those hazards, with ATCo training only (e.g. Incorrect/incomplete input data, Incorrect weather forecast, Data link corrupted, etc.).

Hazards related to some non-regular situations, indicate safety issues that can simply appear in the system, but there are no special measures to prevent their appearance (e.g., Existence of unknown flights, Lack of procedure and/or undefined responsibility for interception of aircraft, Message sent by pilot is not in standard format, Insufficient capacity of an ATC centre, etc.)

One of the most important group of hazards identified categorized as Coordination/Undefined responsibility (III-4/II-4), assumes lack of "master system" or "master" ATCo when solution requires communication between various ATC Systems/ATCos. Those hazards represent serious safety issues. But, if the scenario implementation (S1 or S2) assumes that clear responsibility between ATCo(s) and/or ATC System is pre-defined and ATCos are properly trained to recognize the "hierarchy" in all situations, those hazards will not be relevant any more, i.e. will not be the characteristic of the system that endangers safety.

And last, but the most relevant for the AUTOPACE project, are the hazards which could be mitigated, i.e., safety significance could be reduced through future ATCo training. Those are hazards related to ATCo performances, reduced situation awareness due to boredom/fatigue/overload/too much information shown/ tunnelling, human errorsslips/lapses/mistakes/violations, etc.

To find appropriate mitigation measures, training designers should pay attention to each hazard and its characteristics. It is important to take into Faccount specific scenario/situation, the task hazard is associated to, hazard group I/II/III and values of severity and likelihood.

\section{CONCLUSION}

Tendency to further increase air transport system capacity could put system safety at danger. Increasing capacity without decreasing system safety requires the development of new technologies, operational procedures and corresponding regulations.

In future ATM, a significant increase in automation is expected, in order to cope with growing air transport demand. The automation will take more active role during the provision of the ATC services, while future ATCo will monitor and/or approve actions performed by automated ATC Systems. ATCo will need to be trained to safely adapt to new role, with special emphasis to be prepared for active participation in the case of automated system failure (non-nominal situations). Developing appropriate training should rely on assessed safety hazards in future ATM.

AUTOPACE project is specific because it looks in a far future - 2050 and beyond so qualitative process is single option. This fact together with fact that details for future automation are uncertain makes hazard identification process very challenging. That's why, in order to assess safety hazards, an approach based on hazard identification brainstorming 
sessions with operational experts, combining four well known and complementary methods used in aviation is proposed. Two expert brainstorming sessions were performed based on future tasks and description of nominal and non-nominal situations which were identified at the beginning of the AUTOPACE project. One, with academic experts, resulted with initial set of hazards. The second, with operational experts (experienced ATCos), provided a validation of the initial set and some additional, complementary hazards. Proposed hazard identification approach proved to be very useful for such a challenging project.

Final output from both sessions is the list of operations specific and task specific hazards identified. They were categorized with respect to several criteria: responsibility share, nature of hazard and whether they are internal/external. Also, hazards are categorized with respect to risk mitigation possibilities. Those hazards are subject to further characterization (assignment of severity and likelihood), aiming to determine safety critical hazards that will serve as a safety feed-back for development of new training methods for future ATCos.

\section{ACKNOWLEDGEMENT}

This paper is part of a project that has received funding from the SESAR Joint Undertaking under grant agreement No 699238 (AUTOPACE - Facilitating the Automation Pace, http://autopace.eu/) under European Union's Horizon 2020 research and innovation programme. The opinions expressed herein reflect the author's view only. Under no circumstances shall the SESAR Joint Undertaking be responsible for any use that may be made of the information contained herein.

\section{REFERENCES}

[1] Netjasov, F., Air Transport Safety: An Introduction. Nova Science Publishers, Inc., NY, USA 2015.

[2] AUTOPACE Consortium, Deliverable D2.1-Future Automation Scenarios (v00.02.00), H2020-SESAR-2015-1, 2016.

[3] ICAO (2005). ICAO Accident Prevention Programme. International Civil Aviation Organization, Montreal, Canada.

[4] ICAO (2006). Doc. 9859 - Safety Management Manual (SMM),1st edition, International Civil Aviation Organization, Montreal, Canada.

[5] DOT (2009). Risk Management Handbook. Department of Transportation, USA.

[6] de Jong H., Guidelines for the identification of hazards: How to make unimaginable hazards imaginable? (NLR-CR-2004-094), NLR, Amsterdam, 2004.

[7] FAA/EUROCONTROL ATM Safety Techniques and Toolbox, Safety Action Plan-15 (Version 2.0). US Federal Aviation Administration \& European Organisation for the Safety of Air Navigation. 2007.

[8] Blom, H., Stroeve, S. \& de Jong, H., Safety risk assessment by Monte Carlo simulation of complex safety critical operations, 14th Safety-critical Systems Symposium, UK, 2006.

[9] EUROCONTROL Safety Assessment Methodology - SAM (Version 2.1). European Organisation for the Safety of Air Navigation, 2006.

[10] FAST, The FAST Approach to Discovering Aviation Futures and Associated Hazards, Methodology Handbook. Future Aviation Safety Team, 2006.

[11] ICAO. Doc. 9806 - Human Factors Guidelines for Safety Audits Manual. 1st edition, International Civil Aviation Organization, Montreal, Canada, 2002. 